\title{
POPULATION FLUCTUATIONS OF THE WHITEFLY Bemisia argentifolii BELLOWS AND PERRING AND THE LEAFHOPPERS INFESTING PEACH TREES AND THEIR PREDATORY INSECTS AT MANSOURA DISTRICT. \\ Mohamed, Nadia E. *; A. H. Abdel-Salam** and A. A. A. Saleh* *Plant Protection Res. Institute, Agricultural Research Center, Dokki . ${ }^{* \star}$ Economic Entomology Dept., Fac. of Agric., Mansoura Univ., Egypt.
}

\begin{abstract}
Field studies had been carried out in peach orchard at Mansoura district to investigate the population fluctuations of the Bemisia argentifolii Bellows and Perring and the leafhoppers attacking peach trees and their associated predatory insects during the two successive years (2005 and 2006). In addition, we evaluated the effect of temperature and relative humidity on the population densities of these insects under field conditions.

The obtained results indicated that there were four insect species belonging to Order Homoptera attacking peach trees. These insect pests were $B$. argentifolii ; Empoasca discipiens Poali ; Empoasca lybica de Berg and Agallia aegyptiaca Host. Also, two predators were associated with these insect pests. These predators were Chrysoperla carnea (Steph.) and Exochomus nigromaculatus (Goeze). The data indicated that $A$. aegyptiaca was first record on peach trees at Mansoura district.

Data revealed that $B$. argentifolii had four peaks on peach trees in the two years of study. The highest peak was recoded in the second week of September in 2005 , while that was in the second week of October in 2006. The results showed that temperature had highly positive significant effect on the population densities of this insect. On the other hand, the maximum relative humidity had positive significant effect.

The obtained results recorded that $E$. discipiens had five peaks on peach trees in the first year. Whereas, there were three peaks in the second year of study. The highest peak was found in the third week of July in the two years of study. The statistical analysis showed that temperature components had positive significant effect on the population densities of this insect, while the maximum relative humidity had greatly effect.

The results indicated that E. lybica had five and four peaks in 2005 and 2006, respectively. The statistical analysis showed that the temperature had positive significant effect on the population density of this insect. On the other hand, the maximum relative humidity had greatly effect on the population density of this insect.

The results indicated the $A$. aegyptiaca had four peaks in the first year, whereas five peaks in the second year. The statistical analysis of maximum, minimum and average temperature had highly effect on the population density of this insect, while the maximum relative humidity had greatly effect on the population density of this insect. The results showed that $E$. nigromaculatus had three peaks in the first year. Whereas, five peaks were recorded in the second year of study, while $C$. carnea had four peaks in the two years of investigation.
\end{abstract}

\section{INTRODUCTION}

The silverleaf whitefly, Bemisia argentifolii Bellows and Perring and the potato leafhoppers, Empoasca discipiens Paoli ; Empoasca lybica de Berg (Homoptera : Aleyrodidae and Cicadildidae) are ranked among the most insects attacking field orchard fruits and greenhouse crops around the world 
(Mound and Halsey,1978). The serious damage of these insects to plants results directly from feeding and indirectly through the transmission of plant disease (Coasta, 1976 ; Bird and Maramorosch 1978). Bemisia argentifolii and leafhoppers attack many high value plant hosts of several different families in Egypt (Abd-Rabou, 1997). Several investigators in different part of the world studied the population density of these insects (Mangoud, 2000 ; Ibrahim, 2001 ; Hamed and Chemseddine, 2001 ; El-Sherbenie, 2004 ; Grafton and Montez, 2005 and Ibrahim, 2005). The present work was designed to study the population densities of the silverleaf whitefly $B$. argentifolii and the leafhoppers attacking peach trees and their associated predatory insects at Mansoura district. In addition, we investigate the effect of the temperature and relative humidity on the population density of these insects and their predators .

\section{MATERIALS AND METHODS}

This work was carried out at peach trees (about one feddan) located at Mansoura district in two successive years (2005 and 2006). Peach trees (variety baladi) were eight years old. There were no insecticides applied for two yeas of investigation. Visual count was applied to study the population fluctuations of $B$. argentifolii and the three leafhoppers $E$. discipiens ; $E$. lybica ; A. aegyptiaca and their associated predators during the period of study. Ten trees at the same age and size were chosen at random at the same orchard, in every site for sampling and separated as replicates during the course of this study.

Twenty five peach leaves were collected from each tree and thus 250 leaves were chosen at weekly intervals from peach trees. The samples were initiated from the first week of January till end of December during the two years of study. The peach leaves were carefully investigated and the insects on upper and lower surfaces were recorded. In addition, the same leaves were put in plastic bags tightly closed and transferred to the laboratory of Economic Entomology Department, Faculty of Agriculture, Mansoura University for examination live immature stages of $B$. argentifolii and three leafhoppers were counted on both surfaces of peach leaves under the stereomicroscope and recorded. Identifications were achieved by the aid of the Taxonomy Department, Plant Protection, Research Institute , ARC, Giza , Egypt.

Daily records of temperature and relative humidity during the period of investigation were obtained from the Meteorogical station, Ministry of Defense at Showa Air Base Station about $5 \mathrm{~km}$ from Mansoura. The effect of temperature and relative humidity on the relative abundance of $B$. argentifolii and the three leafhoppers and their associated predators found in peach orchard have been studied. Costat Software Program (1990) was used to compute the effect of these weather factors on the population densities of these insects. The simple correlation coefficients of the relationships between biweekly average of temperature and relative humidity components and the biweekly average number of the $B$. argentifolii and the three leafhoppers infesting peach trees and their predatory insects were computed. 


\section{RESULTS AND DISCUSSION}

\section{A: Bemisia argentifolii}

Figures (1 and 2) showed that $B$. argentifolii had four peaks in the two years of study. The highest peak was found in the second week of September (430 individuals / 250 leaves) during the first year, while that in the second week of October (390 individuals / 250 leaves) in the second year, when the temperature reached $26.0 ; 25.9^{\circ} \mathrm{C}$ and R.H. 69.4 and $64.5 \%$, respectively.
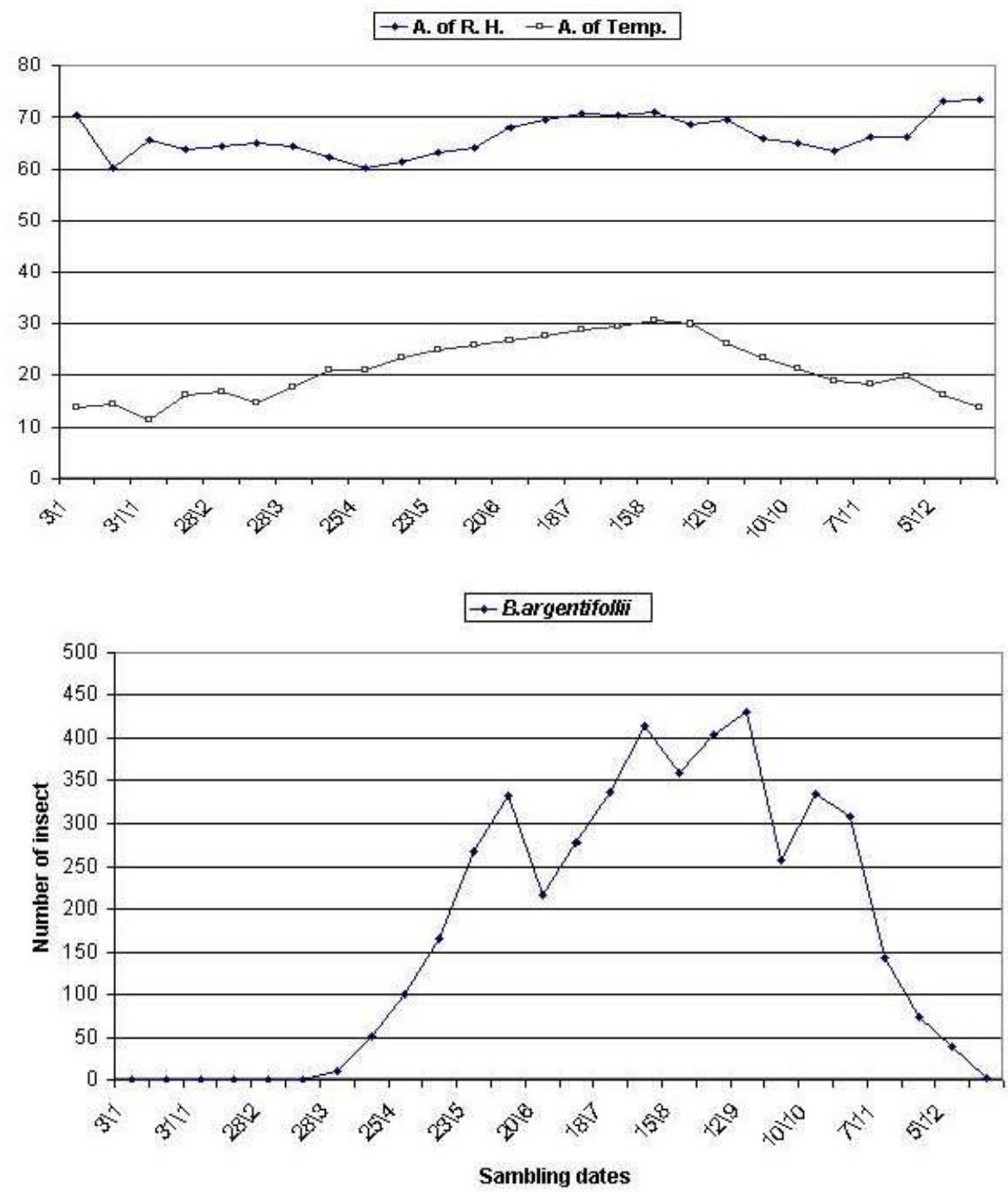

Figure (1): Population fluctuation of $B$. argentifolii infesting peach trees during 2005 at Mansoura district. 

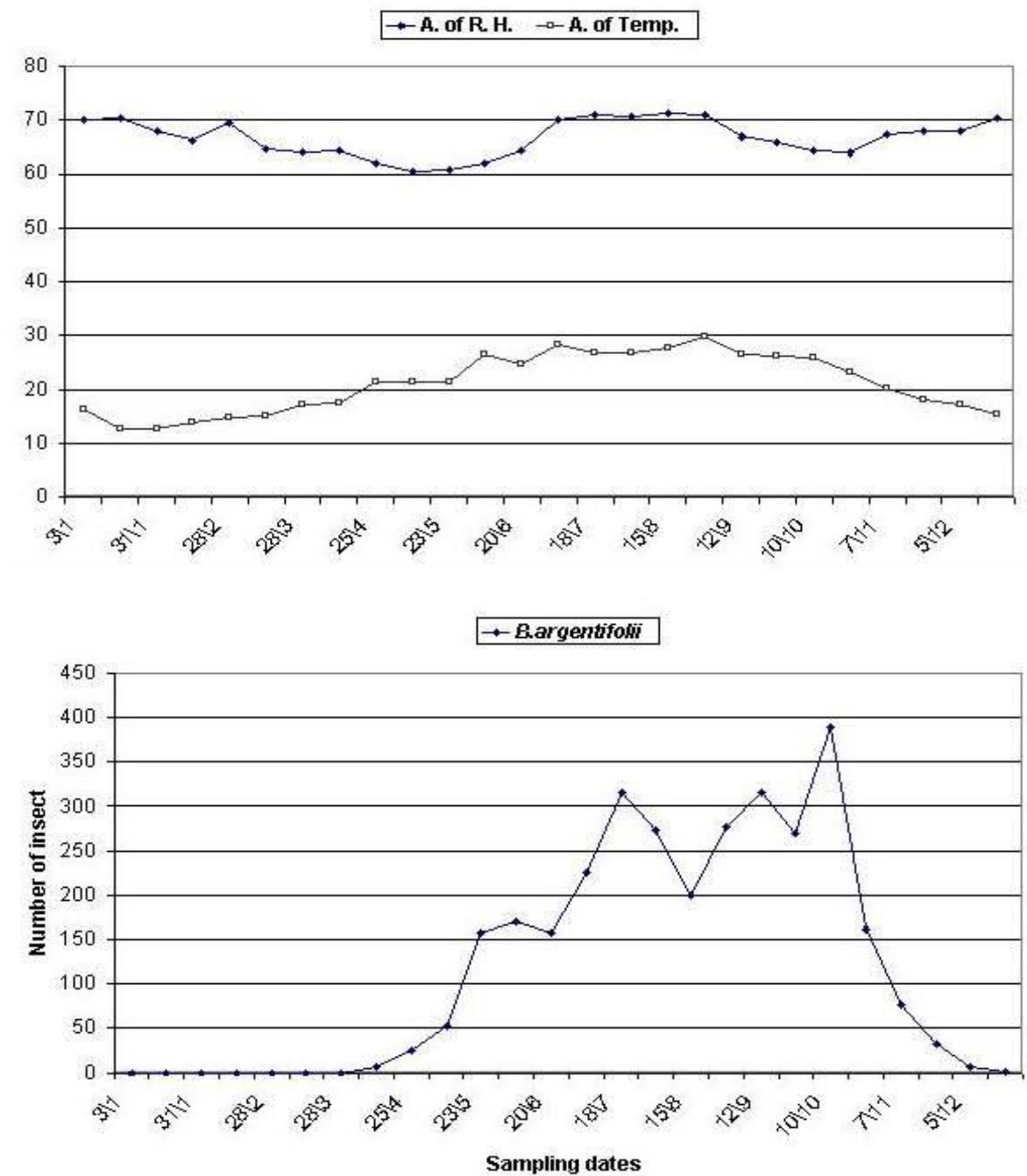

Figure (2): Population fluctuation of $B$. argentifolii infesting peach trees during 2006 at Mansoura district.

The other three peaks in the first year were recorded in the first week of June (332 individuals / 250 leaves), first week of August (414 individuals / 250 leaves) and second week of October (335 individuals / 250 leaves) respectively, when the temperature and relative humidity reached $25.8 ; 29.4$; $21.2^{\circ} \mathrm{C}$ and $64.2 ; 70.4$ and $65.1 \%$ R.H. Whereas, the other three peaks in the second year were recorded in the first week of June (171 individuals / 250 leaves), third week of July (315 individuals / 250 leaves) and in the second week of September (315 individuals / 250 leaves) at an average of 26.6 ; $26.9 ; 26.5^{\circ} \mathrm{C}$ and $62.0 ; 70.9$ and $66.9 \%$ R.H.. 
Data tabulated in Table (1) show the simple correlation between the biweekly insect numbers of $B$. argentifolii and biweekly average temperature and relative humidity components in two successive year (2005 and 2006) at Mansoura district. From this table, it can be seen that the maximum ; minimum and average temperature had highly positive significant effect on the population densities of $B$. argentifolii during the two years of study. The maximum R.H. had showed positive significant impacts on the population density of this insect during 2005 and 2006, while the minimum and average R.H. insignificant impacts on the population densities of this insect during the two years of study.

Table (1): Simple correlation coefficient between the population densities of $B$. argentifolii and the temperature and relative humidity components in peach orchard during 2005 and 2006 at Mansoura district.

\begin{tabular}{|c|c|c|c|c|c|c|}
\hline \multirow[t]{2}{*}{ Weather variable } & \multicolumn{3}{|c|}{2005} & \multicolumn{3}{|c|}{2006} \\
\hline & $\mathbf{R}$ & $\mathbf{P}$ & $\mathbf{S}$ & $\mathbf{R}$ & $\mathbf{P}$ & $\mathbf{S}$ \\
\hline Maximum Temp. & 0.8527 & 3.1789 & *** & 0.8817 & 2.6577 & *** \\
\hline Minimum Temp. & 0.8800 & 3.1345 & *** & 0.8909 & 1.0547 & *** \\
\hline Average Temp. & 0.8742 & 5.3686 & *** & 0.8889 & 1.2984 & $* * *$ \\
\hline Maximum R.H. & 0.5212 & 0.0063 & ** & 0.4142 & 0.0353 & * \\
\hline Minimum R.H. & 0.1130 & 0.5825 & Ns & 0.0028 & 0.9891 & Ns \\
\hline Average R.H. & 0.2510 & 0.2160 & Ns & 0.1132 & 0.5817 & Ns \\
\hline $\begin{array}{l}\text { Ns =insignificant } \\
\text { P = Probability }\end{array}$ & & & & & elatior & \\
\hline
\end{tabular}

\section{B: Empoasca discipiens}

Figures ( 3 and 4 ) revealed that $E$. discipiens had five peaks in the first year and three peaks in the second year of study. The highest peak was found in the third week of July (366 individuals / 250 leaves) and (325 individuals / 250 leaves) during the two years of study, when the temperature reached $28.8 ; 26.9^{\circ} \mathrm{C}$ and R.H. 70.7 and $70.9 \%$ respectively. The other four peaks were recorded in the second week of April (218 individuals), second week of May (331individuals), in the third week of August (235 individuals) and in the second week of September (326 individuals) at an average of temperature $20.9,23.5,30.5,26.0^{\circ} \mathrm{C}$ and $62.3,61.4,71.1$ and $69.4 \%$ R.H., in the first year, while that were in the second week of May (255 individuals) and the second week of September (299 individuals) at an average $21.3 ; 26.5{ }^{\circ} \mathrm{C}$ and R.H. 60.6 and $66.9, \%$ in the second year of study. El-Sherbenie (2004) recorded four peaks in 2000 and 2001 for $E$. discipiens on guava trees and the highest peak was found by mid-August in both years of study.

Data in Table (2) cleared the statistical correlation coefficient between the population densities of $E$. discipiens and temperature degrees and R.H. \% during the two years (2005 and 2006). Maximum, minimum and average temperature had a highly positive significant effect during the two years of study. Maximum R.H. showed a significant effect, while minimum and average R.H. \% insignificant effect during the two years of study. El- 
Mohamed, Nadia E. et al.

Sherbenie (2004) stated that the minimum and maximum temperature showed a highly significant positive correlation on the population density of this insect during 2000 and 2001. The relative humidity parameters exerted a slight significant negative to positive significant correlation during the two years of investigation.
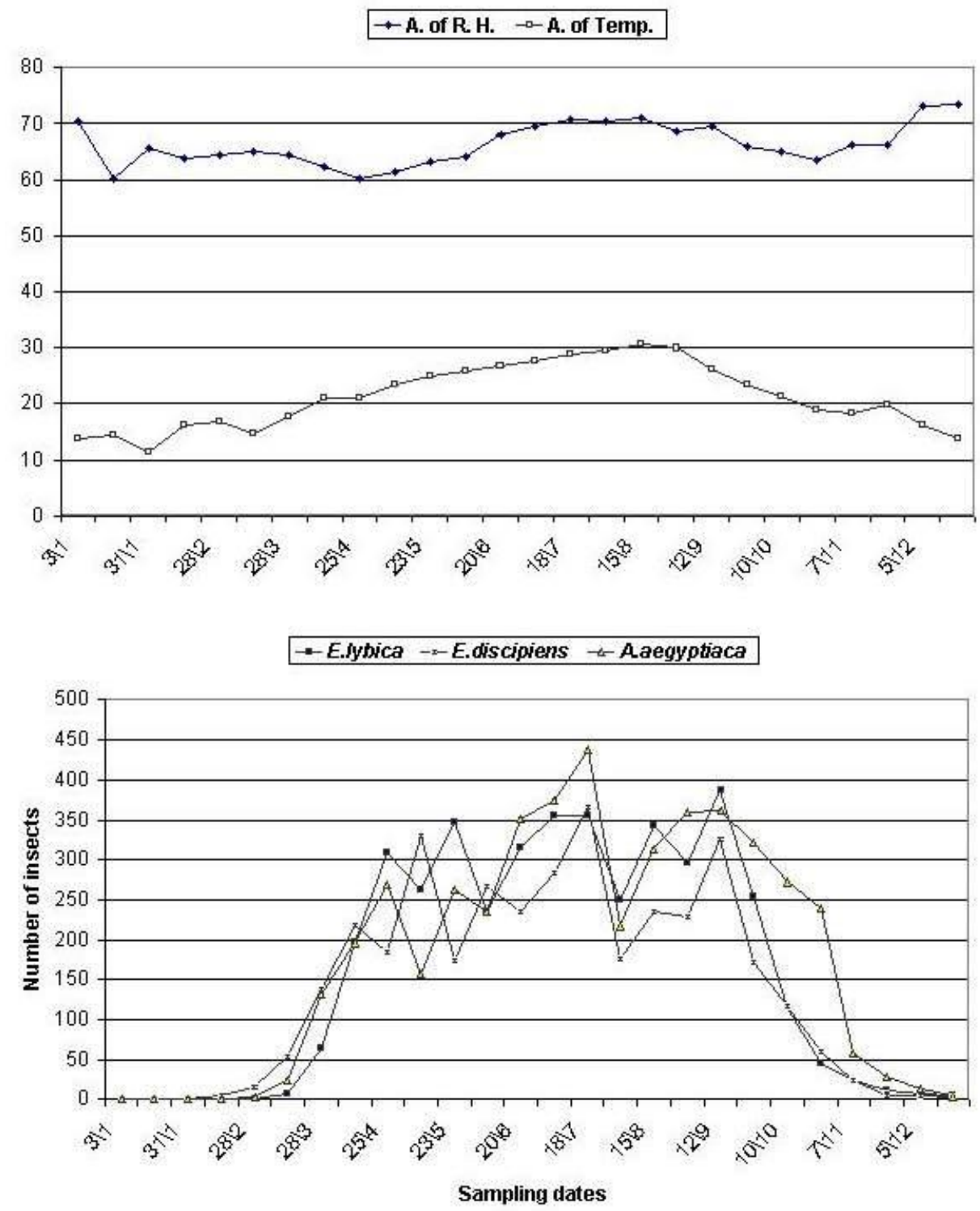

Figure (3):Population fluctuation of the three leafhoppers infesting peach trees during 2005 at Mansoura district. 
J. Agric. Sci. Mansoura Univ., 33 (4), April, 2008

$\rightarrow$ A. of R.H. $\quad \rightarrow$ - A. of Temp.

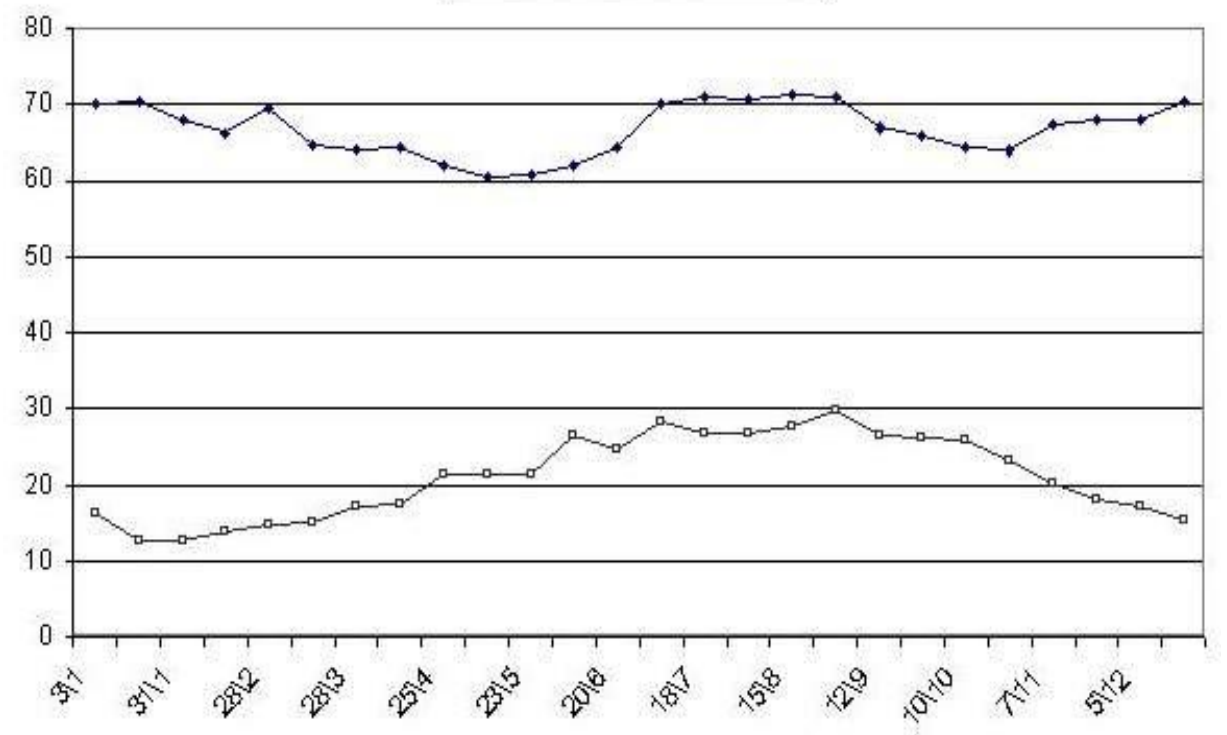

$\rightarrow$ E. jybica $-x-$ E.discipiens $\rightarrow$ A.aegyptiaca

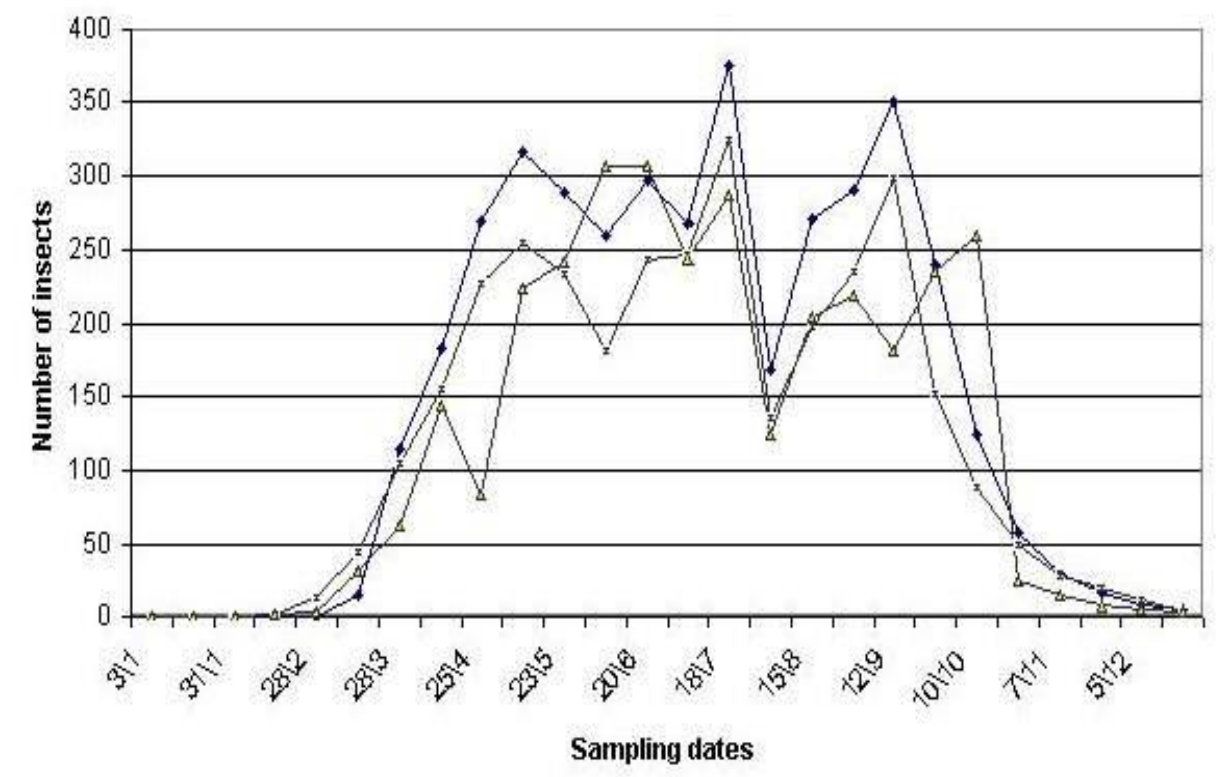

Figure (4) :Population fluctuation of the three leafhoppers infesting peach trees during 2006 at Mansoura district.

2897 
Table (2): Simple correlation coefficient between the population densities of $E$. discipiens and the temperature and relative humidity components in peach orchard during 2005 and 2006 at Mansoura district.

\begin{tabular}{|c|c|c|c|c|c|c|}
\hline \multirow[t]{2}{*}{ Weather variable } & \multicolumn{3}{|c|}{2005} & \multicolumn{3}{|c|}{2006} \\
\hline & $\mathbf{R}$ & $\mathbf{P}$ & $\mathbf{S}$ & $\mathbf{R}$ & $\mathbf{P}$ & $\mathbf{S}$ \\
\hline Maximum Temp. & 0.8680 & 9.2512 & *** & 0.7811 & 2.4859 & 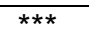 \\
\hline Minimum Temp. & 0.8109 & 5.0498 & $\star * \star *$ & 0.7512 & 9.7301 & $* \star \star$ \\
\hline Average Temp. & 0.8455 & 5.3884 & $\star \star \star *$ & 0.7691 & 4.4104 & $\star \star \star *$ \\
\hline Maximum R.H. & 0.6470 & 3.5315 & *** & 0.4188 & 0.0332 & * \\
\hline Minimum R.H. & -0.1540 & 0.4523 & Ns & -0.3101 & 0.1230 & Ns \\
\hline Average R.H. & 0.0449 & 0.8273 & Ns & -0.2095 & 0.3042 & Ns \\
\hline $\begin{array}{l}\text { Ns =insignificant } \\
P=\text { Probability }\end{array}$ & 0. & with varie & & & & \\
\hline
\end{tabular}

\section{B: Empoasca lybica .}

Figures ( 3 and 4) showed that E. lybica had five peaks in the first year and four peaks in the second year of study. The highest peak was found during the second week of September (387 individuals / 250 leaves) in the first year, while that was in the third week of July (376 individuals /250 leaves) in the second year of study, when the temperature reached $26.0 ; 26.9^{\circ} \mathrm{C}$ and R.H. 69.4 and $70.9 \%$,respectively. The other four peaks in the first year were recorded in the last week of April (308 individuals), in the last week of May (347 individuals), in the third week of June (355 individuals), in the third week of August (342 individuals) at an average of $20.9 ; 24.9 ; 28.8$; $30.5^{\circ} \mathrm{C}$ and $60.2 ; 63.3 ; 70.7$ and $71.1 \%$ R.H. whereas, the other three peaks in the second year were recorded in the second week of May (315 individuals), in the third week of June (297 individuals) and in the second week of September (350 individuals) at an average of $21.3 ; 24.8 ; 26.5 ;{ }^{\circ} \mathrm{C}$ and $60.6 ; 64.5$ and $66.9 \%$ R.H. . These findings agree with those of ElSherbenie (2004), who found that E. lybica had four peaks on guava trees in the two years of study.

Data tabulated in Table (3) show the simple correlation coefficient between the biweekly insect numbers of E. lybica and biweekly average temperature and relative humidity components in the two years of study. From this Table, it can be seen that the maximum, minimum and average temperature had a highly positive significant effect on the population densities of E. lybica during the two years of study. The maximum of R.H. \% showed a significant effect on the population density, while the minimum and average R.H.\% had insignificant impacts on the population densities of this insect during 2005 and 2006. EL-Sherbenie (2004) reported that the minimum and maximum temperature showed highly significant positive correlation on the population densities of E. lybica during the two years (2000 and 2001). 
Table (3): Simple correlation coefficient between the population densities of $E$. lybica and the temperature and relative humidity components in peach orchard during 2005 and 2006 at Mansoura district.

\begin{tabular}{|c|c|c|c|c|c|c|}
\hline \multirow{2}{*}{$\begin{array}{l}\text { Weather } \\
\text { variable }\end{array}$} & \multicolumn{3}{|c|}{2005} & \multicolumn{3}{|c|}{2006} \\
\hline & $\mathbf{R}$ & $\mathbf{P}$ & $\mathbf{S}$ & $\mathbf{R}$ & $\mathbf{P}$ & $\mathbf{S}$ \\
\hline Maximum Temp. & 0.9127 & 8.1340 & $\star \star \star *$ & 0.8176 & 3.3973 & $\star \star \star *$ \\
\hline Minimum Temp. & 0.8676 & 9.5413 & $\star \star \star *$ & 0.7746 & 3.4026 & $\star * \star *$ \\
\hline Average Temp. & 0.8972 & 5.3725 & $\overline{\star \star \star \star *}$ & 0.8004 & 9.1099 & $\overline{* \star \star}$ \\
\hline Maximum R.H. & 0.6667 & 1.9929 & $\star \star \star \star$ & 0.4114 & 0.0367 & * \\
\hline Minimum R.H. & -0.0962 & 0.6399 & Ns & -0.3322 & 0.0972 & Ns \\
\hline Average R.H. & 0.1023 & 0.6189 & Ns & -0.2286 & 0.2612 & Ns \\
\hline $\begin{array}{l}\text { Ns =insignificant } \\
\text { P = Probability }\end{array}$ & significan & $\begin{array}{l}\text { ith varie } \\
\text { icant sig }\end{array}$ & $x \in$ & & & efficie \\
\hline
\end{tabular}

\section{C: Agallia aegyptiaca .}

Figures ( 3 and 4 ) showed that $A$. aegyptiaca had four peaks in the first year, whereas five peaks in the second year. The data indicated that this insect was the first record on peach trees at Mansoura district. The highest peak was found during the third week of July (438 individuals /250 leaves) in the first year, whereas in the third week of June (306 individuals / 250 leaves) in the second year of study, when the temperature reached $28.8 ; 24.8^{\circ} \mathrm{C}$ and R.H. 70.7 and $64.5 \%$,respectively. The other three peaks were recorded in the first year in the last week of April (269 individuals), last week of May (263 individuals) and second week of September (361individuals) at an average of temperature $20.9 ; 24.9 ; 26.0^{\circ} \mathrm{C}$ and $60.2 ; 63.3$ and $69.4 \%$ R.H., while that were in the second week of April (144 individuals), third week of July (288 individuals), last week of August (219 individuals) and second week of October ( 259 individuals) at an average of temperature $17.6 ; 26.9$; $29.7 ; 25.9{ }^{\circ} \mathrm{C}$ and R.H. $64.3 ; 70.9 ; 71.1$ and $64.5 \%$ in the second year of study.

Data in Table (4) cleared the statistical correlation coefficient between the population densities of $A$. aegyptiaca and temperature degrees and R.H. . Maximum, minimum and average temperature affected greatly in the population densities of this insect during the two years of study. While the minimum, average R.H.\% had insignificant effect during the two years of study. Maximum of R.H. showed significant effect during the two years of study. El-Naggar etal (2006) found that the effect of temperature on the adult stage of jassids and whiteflies was positive and insignificantly, while it was negative and insignificantly on immature stage of whiteflies during 2003 and 2004 seasons. 
Mohamed, Nadia E. et al.

Table (4): Simple correlation coefficient between the population densities of $A$. aegyptiaca and the temperature and relative humidity components in peach orchard during 2005 and 2006 at Mansoura district.

\begin{tabular}{|c|c|c|c|c|c|c|}
\hline \multirow[t]{2}{*}{ Weather variable } & \multicolumn{3}{|c|}{2005} & \multicolumn{3}{|c|}{2006} \\
\hline & $\mathbf{R}$ & $\mathbf{P}$ & $\mathbf{S}$ & $\mathbf{R}$ & $\mathbf{P}$ & $\mathrm{S}$ \\
\hline Maximum Temp. & 0.8781 & 3.7389 & $\star \star \star$ & 0.8338 & 1.2177 & 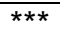 \\
\hline Minimum Temp. & 0.8681 & 9.1486 & $\star \star \star$ & 0.7733 & 3.6177 & $\star \star \star$ \\
\hline Average Temp. & 0.8784 & 3.6451 & $\star \star \star$ & 0.8155 & 3.8635 & 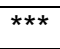 \\
\hline Maximum R.H. & 0.5760 & 0.0020 & ** & 0.4487 & 0.0214 & * \\
\hline Minimum R.H. & -0.0281 & 0.8913 & Ns & -0.3569 & 0.0734 & Ns \\
\hline Average R.H. & 0.1307 & 0.5244 & Ns & 0.2437 & 0.2301 & Ns \\
\hline
\end{tabular}

Figure (5) shows that E. nigromaculatus has been appeared in the last week of March during the two years of study. It recorded three peaks in the first year these peaks found in the last week of April, first week of June and last week of September, whereas in the second year recorded five peaks there were found in the last week of April, in the first week of June, in the third week of July, in the third week of August and in the second week of October .

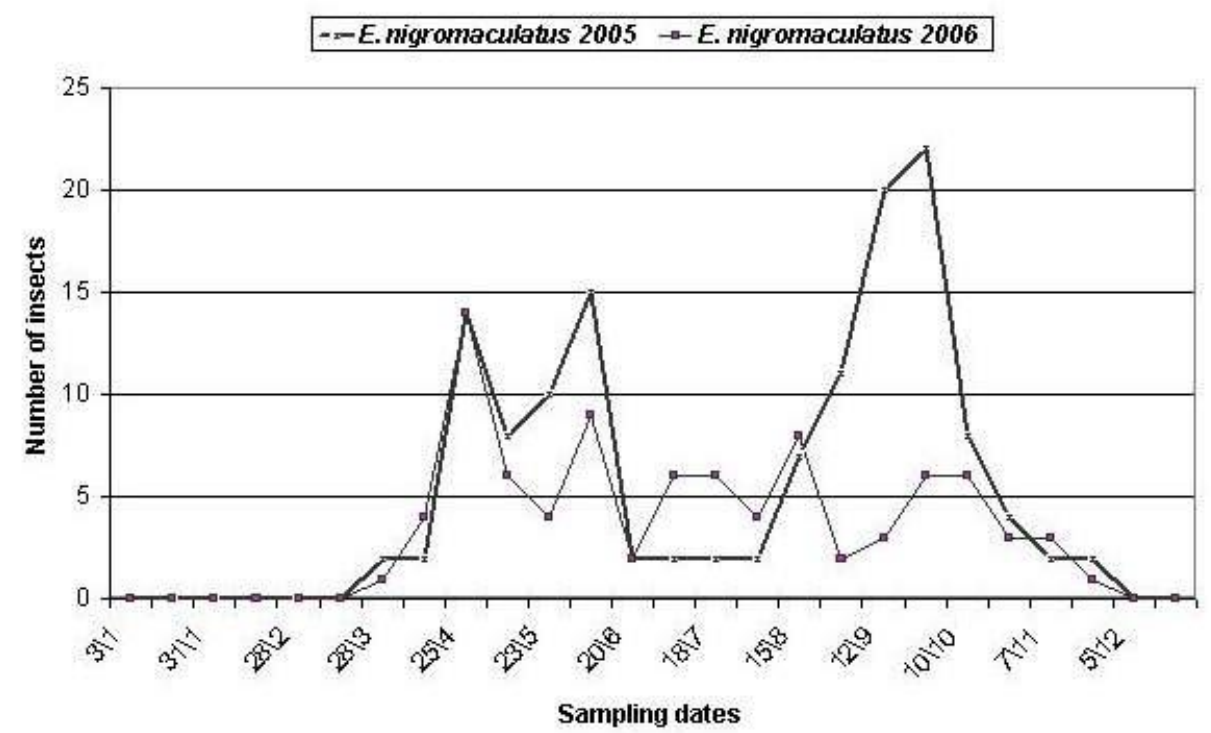

Figure (5): Population fluctuation of $E$. nigromaculatus in peach trees during 2005 and 2006 years at Mansoura district.

Table (5) showed the simple correlation coefficient values between biweekly numbers of $E$. nigromaculatus and certain weather factors on peach trees during 2005 and 2006 . The data indicated that there was a highly 
significant positive effect between the population densities of $E$. nigromaculatus and maximum , minimum and average temperature in the two years of study. Also, there was a significant effect between the population densities of this insect and maximum of R.H., minimum of R.H. in 2005 and 2006 ,respectively, whereas minimum , average and maximum, average of R.H. insignificant in 2005 and 2006 , respectively

Table (5):Simple correlation coefficient between the population densities of $E$. nigromaculatus and the temperature and relative humidity components peach orchard during 2005 and 2006 at Mansoura district.

\begin{tabular}{|c|c|c|c|c|c|c|}
\hline \multirow[t]{2}{*}{ Weather variable } & \multicolumn{3}{|c|}{2005} & \multicolumn{3}{|c|}{2006} \\
\hline & $\mathbf{R}$ & $\mathbf{P}$ & $\mathbf{S}$ & $\mathbf{R}$ & $\mathbf{P}$ & S \\
\hline Maximum Temp. & 0.5316 & 0.0052 & $\star *$ & 0.6426 & 3.9968 & $* * *$ \\
\hline Minimum Temp. & 0.4388 & 0.0249 & * & 0.5751 & 0.0021 & ** \\
\hline Average Temp. & 0.4902 & 0.0110 & * & 0.6193 & 7.4097 & $\star \star \star$ \\
\hline Maximum R.H. & 0.4228 & 0.0313 & * & 0.2975 & 0.1398 & Ns \\
\hline Minimum R.H. & -0.3457 & 0.835 & $\mathrm{Ns}$ & -0.4493 & 0.0212 & * \\
\hline Average R.H. & -0.1566 & 0.4448 & Ns & -0.3578 & 0.0726 & $\mathrm{Ns}$ \\
\hline $\begin{array}{l}\text { Ns =insignificant } \\
P=\text { Probability }\end{array}$ & & & & & & \\
\hline
\end{tabular}

Figure (6) revealed that $C$. carnea had four peaks in the two years of study. There were found in the second week of May, in the first week of June, in the first week of August and in the second week of October in the first year, whereas in the last week of April, in the first week in June, in the third week of August and in the second week of September in the second year of study .

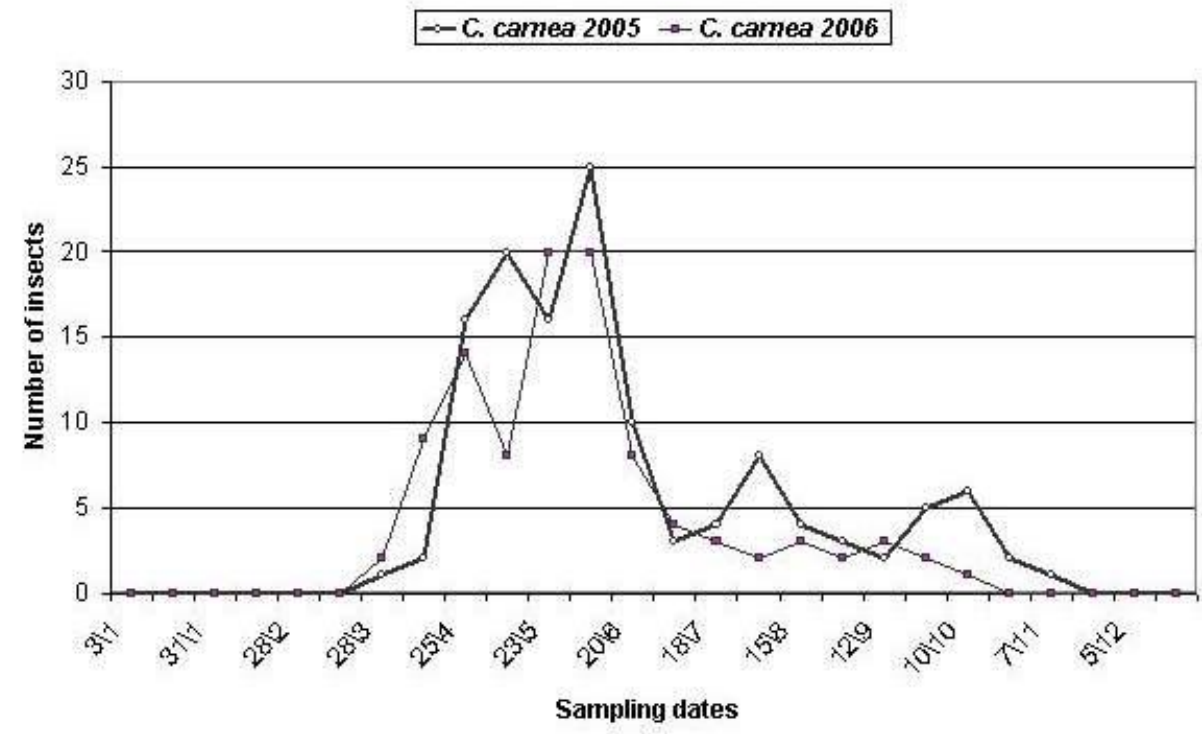

Figure (6): Population fluctuation of $\boldsymbol{C}$. carnea in peach trees during 2005 and 2006 years at Mansoura district. 
Table (6) shows the simple correlation coefficient values between biweekly numbers of $C$. carnea and certain weather factors on peach trees during 2005 and 2006 . The data indicated that there was a significant positive effect between the population densities of $C$. carnea and maximum, minimum, average temperature and maximum, minimum of R.H. in the first year of study . In addition, there was a significant negative effect between the population densities of this insect and minimum, average of R.H. in the second year of study. The present results came in the same line with Ibrahim (2005) who mentioned that the correlation coefficient between temperature variables and C. carnea numbers were significant during 2002 and 2003. Moreover, R.H. variables showed insignificant effect on this insect population, except the effect of the maximum R.H. in 2003 was significant.

Table (6): Simple correlation coefficient between the population densities of $C$. carnea and the temperature and relative humidity components in peach orchard during 2005 and 2006 at Mansoura district.

\begin{tabular}{l|c|c|c|c|c|c|}
\hline \multirow{2}{*}{ Weather variable } & \multicolumn{3}{|c|}{$\mathbf{2 0 0 5}$} & \multicolumn{3}{|c|}{$\mathbf{2 0 0 6}$} \\
\cline { 2 - 7 } & $\mathbf{R}$ & $\mathbf{P}$ & $\mathbf{S}$ & $\mathbf{R}$ & $\mathbf{P}$ & $\mathbf{S}$ \\
\hline Maximum Temp. & 0.5016 & 0.0090 & ${ }^{*}$ & 0.3665 & 0.0654 & $\mathrm{Ns}$ \\
\hline Minimum Temp. & 0.4080 & 0.0385 & ${ }^{*}$ & 0.2088 & 0.3058 & $\mathrm{Ns}$ \\
\hline Average Temp. & 0.4627 & 0.0172 & ${ }^{*}$ & 0.3018 & 0.1340 & $\mathrm{Ns}$ \\
\hline Maximum R.H. & 0.4808 & 0.0128 & ${ }^{*}$ & 0.2859 & 0.1566 & $\mathrm{Ns}$ \\
\hline Minimum R.H. & -0.5057 & 0.0083 & ${ }^{*}$ & -0.7344 & 1.9361 & ${ }^{* \star *}$ \\
\hline Average R.H. & -0.3481 & 0.0813 & Ns & -0.6470 & 3.5406 & ${ }^{* * *}$ \\
$\begin{array}{l}\text { Ns =insignificant } \\
\text { P = Probability }\end{array}$ & $\begin{array}{l}\text { * significant with varied degree where R= Correlation coefficient } \\
\text { S = significant sign }\end{array}$
\end{tabular}

\section{REFERENCES}

Abd-Rabou, S. (1997). Hosts, distribution and vemacular names of whiteflies (Homoptera: Aleyrodidae) in Egypt. Ann. Agric. Sci. Agric. Sci. Moshtohor, $35: 1029-1048$.

Bird, J. and Moramorosch, K.(1978).Viruses and viruses disease Associated with whiteflies. Advances in virus Research,22: 55- 109.

Coasta, S. (1976). Whitefly-transmitted plant diseases. Ann. Rev. Phytopath. 14 : 429-449.

Costat Software, (1990). Microcomputer program analysis, version 4.20, CoHort Software, Berkly, CA, USA..

El-Naggar, J. B. ; R. A. A. El-Doksh and S. A. Aref (2006). Efficiency of some compounds and some weather factors on some piercing -sucking insects and their associated natural predators in cotton fields . J. Agric. Sci. Mansoura Univ. , 31 (4) : $2405-2413$.

El- Sherbemie, M. K. G. (2004). Role of established predatory insects in suppressing the population density of injurious insects infesting guava orchards at Dakahlia Governorate. M. SC. .thesis, Fac. Agric., Mans. Univ. pp. 121 
Grafton-Cardwell, E.; P. Gu and G. Montez (2005). Effects of temperatures on development of vedalia beetle Rodolia cardinalis (Mulsant). Biological Control.32 (3): $473-478$.

Hamed, T. and M. Chemseddine (2001). Assessment of temperature effects on the development and fecundity of Pllus mediterraneus (Col. , Coccinellidae) and consumption of Saissetia oleae eggs (Hom. , Coccidae ). J . Appl. Ent. , 125 (9) : 527 - 531

Ibrahim, M. M. E. (2001). Ecological and biological studies on major grape pests in Dakahlia Governorate . M. Sc.. thesis, Fac. Agric. , Mans. Univ. pp. 102.

(2005). Ecological and biological studies on persimmon ( Diospyros kaki, L. pest and their natural enemies. Ph. D. Sc. Thesis, Fac. Agric. Mans. Univ. pp. 145.

Mangoud, A. A. (2000). Integrated pest management of apple trees. Ph. D.Thesis, Fac. Agric., Cairo Univ. pp. 236.

Mound, L. A. and Halsey, S. H. (1978). Whitefly of the world. Brit. Museum NY, NY: 340.

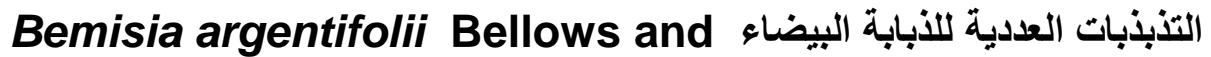
فئطاطات الأوراق التي تصيب أثخار الخوخ و مفترسساتها الحشرية Perring في منطقة المنصورة .

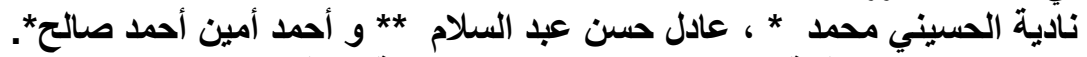

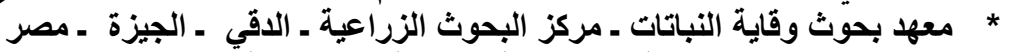

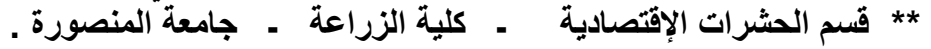

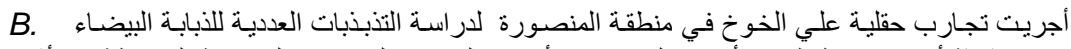

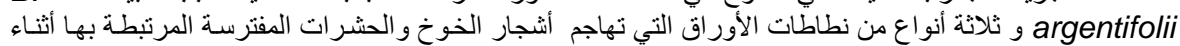

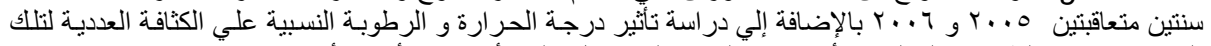

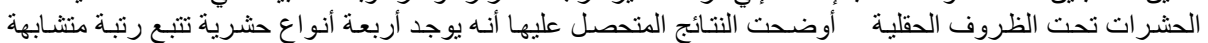

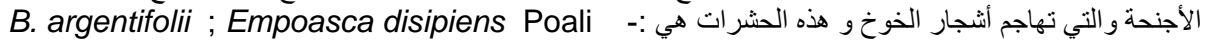

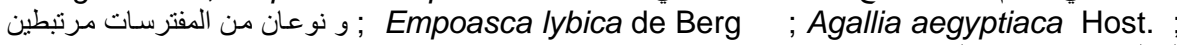

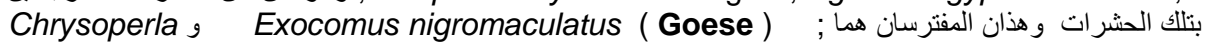
carnea ( Steph.)

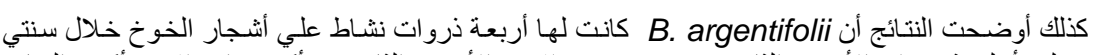
الخوخ.

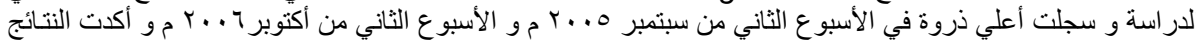

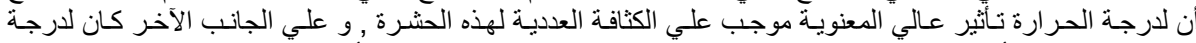

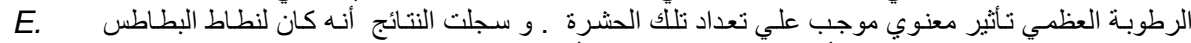
ووجئ discipiens

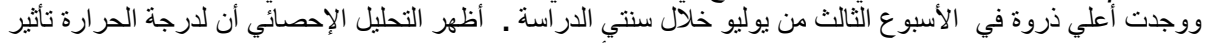

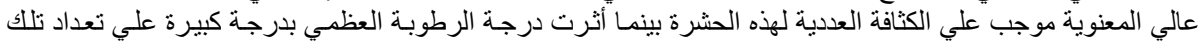

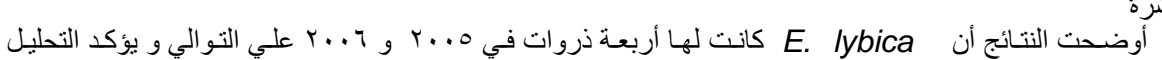

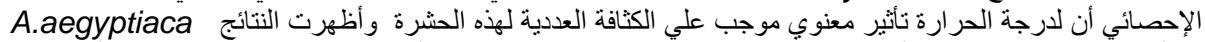

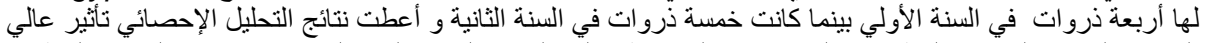

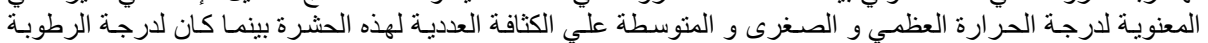

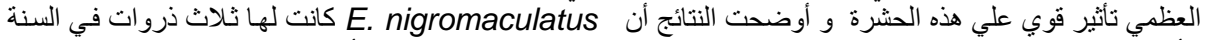

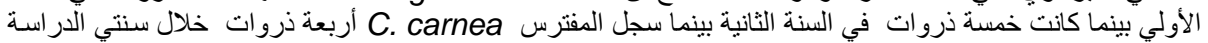

